\title{
Front Matter: Volume 6722
}

, "Front Matter: Volume 6722," Proc. SPIE 6722, 3rd International Symposium on Advanced Optical Manufacturing and Testing Technologies: Advanced Optical Manufacturing Technologies, 672201 (30 November 2007); doi: $10.1117 / 12.784223$

SDIE Event: 3rd International Symposium on Advanced Optical Manufacturing and Testing Technologies: Large Mirrors and Telescopes, 2007, Chengdu, China 


\title{
PROCEEDINGS OF SPIE
}

\author{
3rd International Symposium on \\ Advanced Optical Manufacturing \\ and Testing Technologies
}

\section{Advanced Optical Manufacturing Technologies}

\author{
Li Yang \\ Yaolong Chen \\ Ernst-Bernhard Kley \\ Rongbin Li \\ Editors

\section{8-12 July 2007} \\ Chengdu, China
}

Sponsored by

COS-The Chinese Optical Society (China) • IOE-The Institute of Optics and Electronics, CAS (China)

Technical Cosponsor

SPIE

Cosponsoring Organizations

State Key Laboratory of Optical Technology for Microfabrication (China) • SOS—Sichuan Optical Society (China)

\section{Cooperating Organization}

Committee of Optical Manufacturing Technology, COS (China)

\section{Supporting Organizations}

Ministry of Science and Technology of China (China) • Chinese Academy of Sciences (China) • National Natural Science Foundation of China (China)

Published by

SPIE

Volume 6722

Part One of Two Parts 
The papers included in this volume were part of the technical conference cited on the cover and title page. Papers were selected and subject to review by the editors and conference program committee. Some conference presentations may not be available for publication. The papers published in these proceedings reflect the work and thoughts of the authors and are published herein as submitted. The publisher is not responsible for the validity of the information or for any outcomes resulting from reliance thereon.

Please use the following format to cite material from this book:

Author(s), "Title of Paper," in 3rd International Symposium on Advanced Optical Manufacturing and Testing Technologies: Advanced Optical Manufacturing Technologies, edited by Li Yang, Yaolong Chen, Ernst-Bernhard Kley, Rongbin Li, Proceedings of SPIE Vol. 6722 (SPIE, Bellingham, WA, 2007) Article CID Number.

ISSN 0277-786X

ISBN 9780819468796

Published by

SPIE

P.O. Box 10, Bellingham, Washington $98227-0010$ USA

Telephone +1 3606763290 (Pacific Time) · Fax +1 3606471445

SPIE.org

Copyright (C) 2007, Society of Photo-Optical Instrumentation Engineers

Copying of material in this book for internal or personal use, or for the internal or personal use of specific clients, beyond the fair use provisions granted by the U.S. Copyright Law is authorized by SPIE subject to payment of copying fees. The Transactional Reporting Service base fee for this volume is $\$ 18.00$ per article (or portion thereof), which should be paid directly to the Copyright Clearance Center (CCC), 222 Rosewood Drive, Danvers, MA 01923. Payment may also be made electronically through CCC Online at copyright.com. Other copying for republication, resale, advertising or promotion, or any form of systematic or multiple reproduction of any material in this book is prohibited except with permission in writing from the publisher. The CCC fee code is 0277-786X/07/ 18.00 .

Printed in the United States of America.

Publication of record for individual papers is online in the SPIE Digital Library.

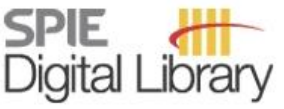

SPIEDigitalLibrary.org

Paper Numbering: Proceedings of SPIE follow an e-First publication model, with papers published first online and then in print and on CD-ROM. Papers are published as they are submitted and meet publication criteria. A unique, consistent, permanent citation identifier (CID) number is assigned to each article at the time of the first publication. Utilization of CIDs allows articles to be fully citable as soon they are published online, and connects the same identifier to all online, print, and electronic versions of the publication. SPIE uses a six-digit CID article numbering system in which:

- The first four digits correspond to the SPIE volume number.

- The last two digits indicate publication order within the volume using a Base 36 numbering system employing both numerals and letters. These two-number sets start with 00, 01, 02, 03, 04, 05 , $06,07,08,09,0 A, 0 B \ldots 0 Z$, followed by 10-1Z, 20-2Z, etc.

The CID number appears on each page of the manuscript. The complete citation is used on the first page, and an abbreviated version on subsequent pages. Numbers in the index correspond to the last two digits of the six-digit CID number. 


\title{
Contents
}

\section{Part One}

\author{
xix Conference Committee \\ xxi Symposium Committees \\ $x x$ iii Introduction \\ XV Attendees of AOMATT 2007 photo
}

\section{SESSION 2-1}

672202 Molding technology of optical plastic refractive-diffractive lenses [6722-01]

Q. Xin, H. Liu, P. Lu, F. Gao, B. Liu, Chengdu Crystal Technology Co., Ltd. (China)

672203 Optical design in packaging and illuminating system for high power light-emitting diodes for projection system [6722-02]

C. Shen, Zhejiang Univ. (China) and China JiLiang Univ. (China); H. Feng, Z. Xu, Zhejiang Univ. (China); S. Jin, China JiLiang Univ. (China)

672204 Calculating subtool pressures by using genetic algorithms [6722-03]

A. Cordero-Dávila, L. Téllez-Arriaga, Benemérita Univ. Autónoma de Puebla (Mexico); J. González-García, Univ. Technológica de la Mixteca (Mexico); C. I. Robledo-Sánchez, J. Cuautle-Cortéz, J. d. J. Díaz-Anzures, L. A. Martinez-Medina, Benemérita Univ. Autónoma de Puebla (Mexico)

672205 An analytical method for curved optical waveguides [6722-04]

T. Zhang, X. Zhang, C. Ji, Y. Cui, Southeast Univ. (China)

672206 \$300 Hartmann field flattening laser beam expander [6722-05]

P. Hao, L. Yuan, K. Li, S. Zhou, Tongji Univ. (China)

672207 Diamond turning aspheric projector mirrors [6722-06]

W. Jiang, LPI Precision Optics, Ltd. (Hong Kong China)

672208 Fabrication of $x$-ray diffractive optical elements for ICF target diagnosis [6722-07] X. Zhu, D. Wang, C. Xie, Institute of Microelectronics (China); L. Cao, J. Yang, China Academy of Engineering Physics (China); T. Ye, J. Niu, B. Chen, M. Liu, Institute of Microelectronics (China)

672209 Experimental study on KDP crystal polishing [6722-08]

B. L. Wang, H. Gao, Dalian Univ. of Technology (China)

67220 A Process optimization of DLC films by unbalanced magnetron sputtering for laser-induced damage threshold improvement [6722-09]

J. Xu, Xi'an Institute of Technology (China) and Northwestern Polytechnical Univ. (China);

J. Su, W. Liu, Xi'an Institute of Technology (China); H. Fan, S. Xie, Northwestern Polytechnical Univ. (China) 
6722 OB Measurement of spatio-temporal dynamics of patterns in dielectric barrier discharge by using a special optical design [6722-10]

W. Fan, L. Dong, R. Gao, F. Liu, Y. He, Hebei Univ. (China)

6722 OC Design for progressive addition lenses [6722-11]

Q. Wu, Univ. Of Science and Technology of Suzhou (China), Soochow Univ. (China), and Wenzhou Medical College (China); L. Qian, Soochow Univ. (China); J. Yu, Soochow Univ. (China), Wenzhou Medical College (China), and Ministry of Health (China); H. Chen, Y. Wang, Wenzhou Medical College (China) and Ministry of Health (China)

6722 OD Research on the AI-AIN granular films prepared by D.C. magnetism filter arc deposition [6722-12]

H. Liang, Y. Zhou, C. Cai, Xi'an Technological Univ. (China)

6722 OE 3D reconstruction from integral images [6722-13]

C. Wu, Q. Wang, Y. Yang, G. Fu, H. Wang, Univ. of Science and Technology Beijing (China)

6722 OF Research on key techniques of nanometer scale macro-micro dual-drive precision positioning [6722-14]

X. Xie, R. Du, Shenzhen Institute of Advanced Integration Technology/The Chinese Univ. of Hong Kong (Hong Kong China)

$67220 \mathrm{G}$ Ferroelectric properties of multi-layer $\mathrm{LiTaO}_{3}$ thin films with $\mathrm{Ta}_{2} \mathrm{O}_{5}$ buffer [6722-15] D.-Y. Zhang, W.-D. Peng, Civil Aviation Flight Univ. of China (China); J.-H. Li, K. Li, Jiangsu Polytechnic Univ. (China); D.-G. Huang, Univ. of Electronic Science and Technology (China)

$6722 \mathrm{OH} \quad$ Q-switched Yb-doped rod-type photonic crystal fiber laser [6722-16]

S. Ruan, C. Guo, P. Yan, C. Du, R. Zhou, Shenzhen Univ. (China)

6722 Ol Preparation and properties of GaP films on ZnS substrate [6722-17]

L. Dong, Y. Sun, X. He, Changchun Univ. of Science and Technology (China)

SESSION 2-3

6722 0J Forecasting model for the machining accuracy of aspheric surface [6722-18]

D. Chen, Y. Zhang, F. Zhang, Harbin Institute of Technology (China)

6722 OK Development of TIF based figuring algorithm for deterministic pitch tool polishing [6722-19] H.-S. Yi, Korea Research Institute of Standards and Science (South Korea); S.-W. Kim, Yonsei Univ. (South Korea); H.-S. Yang, Y.-W. Lee, Korea Research Institute of Standards and Science (South Korea)

$6722 \mathrm{OL}$ Fabrication of multilayer laminar grating with high efficiency for extreme ultraviolet [6722-20]

L.-C. Zhang, Changchun Institute of Optics, Fine Mechanics and Physics (China) and Graduate School of the Chinese Academy of Sciences (China); H. Lin, Tsinghua Univ. (China); C.-S. Jin, Changchun Institute of Optics, Fine Mechanics and Physics (China); H.-J. Zhou, T.-L. Huo, Univ. of Science and Technology of China (China) 
$67220 \mathrm{M}$ Time-resolved dynamics of $\mathbf{3 5 5}$-nm laser-irradiated surface damage on fused silica [6722-21]

S. Xu, China Academy of Engineering Physics (China) and Univ. of Electronic Science and Technology of China (China); X. Yuan, W. Zheng, China Academy of Engineering Physics (China); X. Zu, Univ. of Electronic Science and Technology of China (China); H. LV, X. Jiang, H. Wang, J. Huang, China Academy of Engineering Physics (China)

$67220 \mathrm{~N}$ Methods for integrated simulation of high-precision space opto-mechanical systems [6722-22]

D. Wang, Changchun Institute of Optics, Fine Mechanics and Physics (China) and Graduate School of the Chinese Academy of Sciences (China); G. Jin, H. Yang, Changchun Institute of Optics, Fine Mechanics and Physics (China)

672200 Process monitoring and analysis of atmospheric pressure plasma polishing method [6722-23]

J. Zhang, B. Wang, S. Dong, Harbin Institute of Technology (China)

6722 OP Replication fidelity improvement of PMMA microlens array based on weight evaluation and optimization [6722-24]

B. Jiang, L. Shen, H. Peng, X. Yin, Central South Univ. (China)

\section{SESSION 2-4}

$67220 Q \quad$ Optical design for digital-micromirror device-based infrared scene projector [6722-25] $X$. Jia, Institute of Optics and Electronics (China) and Graduate School of the Chinese Academy of Sciences (China); T. Xing, Institute of Optics and Electronics (China)

6722 OR Research on long focal length on-axis TMA system for high-resolution remote sensing [6722-26]

X. Zhong, L. Zhang, Changchun Institute of Optics, Fine Mechanics and Physics (China) and Graduate School of the Chinese Academy of Sciences (China); G. Jin, Changchun Institute of Optics, Fine Mechanics and Physics (China)

6722 OS Design and fabrication of $x$-ray Kirkpatrick-Baez microscope for ICF [6722-27]

B. Mu, Z. Wang, S. Huang, S. Yi, Z. Shen, Tongji Univ. (China)

6722 OT Determination of optical constants of zirconia and silica thin films in UV to visible range [6722-28]

W. Jin, Changchun Institute of Optics, Fine Mechanics and Physics (China) and Graduate School of the Chinese Academy of Science (China); C. Jin, Changchun Institute of Optics, Fine Mechanics and Physics (China); H. Zhu, L. Liu, Changchun Institute of Optics, Fine Mechanics and Physics (China) and Graduate School of the Chinese Academy of Science (China); H. Yang, Changchun Institute of Optics, Fine Mechanics and Physics (China)

6722 OU Fabrication of flat and supersmooth surfaces with bowl-feed polishing process [6722-29] Z. Shen, B. Ma, Z. Wang, Tongji Univ. (China); Y. Ji, T. Liu, H. Liu, Tianjin Jinhang Institute of Technology Physics (China)

6722 OV Analysis of the force properties of photonic crystal fiber in the v-groove [6722-30] S. Ma, W. Bi, G. Fu, G. Wu, Yanshan Univ. (China) 
$6722 \mathrm{OW}$ Influence of simulation environment on properties of swing system [6722-31]

Y. Zhang, Y. Han, Y. Zhou, J. Han, W. Yao, Harbin Institute of Technology (China)

6722 OX Fabrication of waveguide with ferroelectric-domain structure on electro-optical crystal slice [6722-32]

G. Cui, Y. Li, J. Chen, H. Liu, J. Xu, Q. Sun, Nankai Univ. (China)

\section{SESSION 2-5}

6722 OY Research of digital MTF test system based on CCD [6722-33]

L. Yang, Xi'an Technological Univ. (China) and Xi'an Univ. of Technology (China); G. Sun, W. Ma, Z. Huang, Xi'an Technological Univ. (China)

$67220 \mathrm{OZ}$ Study on the effects of depositing parameters on the protection performance of plasma polymerized hexamethyldisiloxane coatings [6722-34]

R. Zhang, X. Zhu, Univ. of Shanghai for Science and Technology (China); C. Pan, Huangshi Institute of Technology (China)

672210 Computer-controlled fluid jet polishing [6722-35]

P. Guo, Suzhou Univ. (China); H. Fang, Suzhou Univ. (China) and Suzhou Institute of Nano-tech and Nano-bionics (China); J. Yu, Suzhou Univ. (China)

672211 Design of high-resolution Fourier transform lens [6722-36]

L. Zhang, X. Zhong, Changchun Institute of Optics, Fine Mechanics and Physics (China) and Graduate School of Chinese Academy of Sciences (China); G. Jin, Graduate School of Chinese Academy of Sciences (China)

672212 Influence on optical and electrical properties of silver layer by adjoining $\operatorname{Ta}_{2} \mathrm{O}_{5}$ layers [6722-37]

P. Zhao, D. Liu, Shanghai Institute of Technical Physics (China); X. Xu, Donghua Univ.

(China); F. Zhang, Shanghai Institute of Technical Physics (China)

\section{SESSION 2-6}

672213 Special techniques in ultra-precision machining [6722-38]

L. Li, X. Min, D. Chen, J. Wang, ShangHai HongMai Photonic Limit Co. (China)

672214 Super-resolved imaging system with oversampling technology [6722-39]

$X$. Zhang, Changchun Institute of Optics, Fine Mechanics and Physics (China); Y. Liu, J. Zhang, L. Wang, Changchun Institute of Optics, Fine Mechanics and Physics (China) and Graduate School of Chinese Academy of Sciences (China)

672215 Research on the technology of fluorescence separation from exciting light for LIF detection [6722-40]

Y. Shi, L. Wang, Zhejiang Univ. (China); H. Zheng, Zhejiang Univ. (China) and Fujian Normal Univ. (China); J. Wang, Z. Lu, Zhejiang Univ. (China)

672216 Optical method for evaluating the impact response of 1" HDD arm [6722-41]

Y. Fujii, Gunma Univ. (Japan); D.-W. Shu, Nanyang Technological Univ. (Singapore) 
672217 Comparative studies of sol-gel $\mathrm{SiO}_{2}$ thin films prepared by spin-coating and dip-coating techniques [6722-42]

$X$. He, Shanghai Institute of Ceramics (China) and Graduate School of the Chinese Academy of Sciences (China); J. WU, X. Gao, L. Wu, X. Li, Shanghai Institute of Ceramics (China)

\section{POSTER SESSION}

672218 Adaptive optics image deconvolution based on a modified Richardson-Lucy algorithm [6722-43]

B. Chen, Information Engineering Univ. (China) and Guilin Air Force Academy (China);

Z. Geng, X. Yan, Information Engineering Univ. (China); Y. Yang, Guilin Air Force Academy (China); X. Sui, Z. Zhao, Information Engineering Univ. (China)

672219 Manufacturing and photoelectrical properties of P-doped a-Si:H thin films deposited by PECVD [6722-44]

N. Liao, W. Li, Y. Jiang, Y. Kuang, K. Qi, Z. Wu, S. Li, Univ. of Electronic Science and Technology of China (China)

67221 A Application of neural network and spheric harmonics function to system error correction of electro-optical tracker system with X-Y gimbal [6722-45]

$X$. Liu, Institute of Optics and Electronics (China)

6722 1B Selection of neural network structure for system error correction of electro-optical tracker system with horizontal gimbal [6722-46]

$X$. Liu, Institute of Optics and Electronics (China); M. Cen, Chongqing Univ. of Posts and Telecommunications (China)

6722 1C All-dielectric broadband non-polarizing parallel plate beam splitter operating between 450-650nm [6722-47]

W. Wang, Institute of Optics and Electronics (China) and Graduate School of the Chinese Academy of Sciences (China); S. Xiong, Y. Zhang, Institute of Optics and Electronics (China)

6722 1D High power high brightness laser source for material processing through incoherent beam combination [6722-48]

J. Xu, S. Zhao, S. Zhan, R. Hou, Y. Li, L. Shi, S. Fang, Air Force Engineering Univ. (China)

6722 lE Analysis of laser-induction hybrid cladding processing conditions [6722-49]

Y. Huang, Huazhong Univ. of Science and Technology (China) and Huazhong Agricultural Univ. (China); X. Zeng, Q. Hu, Huazhong Univ. of Science and Technology (China)

6722 IF Fabrication of electrospun nanofibers bundles [6722-50]

J. Ye, D. Sun, Xiamen Univ. (China)

6722 1G Design of an aspheric system of optical probe for visibility meter [6722-51]

D. Liu, Changchun Univ. of Science and Technology (China); J. Shen, Changchun Univ. of Technology (China); Y. Sun, Y. Shen, Changchun Univ. of Science and Technology (China) 
$67221 \mathrm{H}$ Study on the optical properties of a one-dimensional periodic multi-layered thin film with gain [6722-52]

L. Liang, C. Zhou, Xi'an Univ. of Architecture and Technology (China)

$672211 \quad$ Stratified scattering model for inhomogeneous dielectric multilayer coatings [6722-53] H. H. Hou, Y. Fan, Changshu Institute of Technology (China); C. R. Xue, Shanghai Institute of Optics and Fine Mechanics (China); J. H. Xing, Changshu Institute of Technology (China)

6722 IJ Influence of cutting parameters on diamond turning titanium alloy [6722-54]

Y. Zhang, Z. Zhou, W. Xiu, Dalian Univ. of Technology (China); Z. Xia, China Academy of Engineering Physics (China)

$67221 \mathrm{~K}$ Analysis for dynamics decoupling of photoelectric tracking system with collimated axis eccentricity [6722-55]

Z. XU, J. Chen, Institute of Optics and Electronics (China) and Graduate School of the Chinese Academy of Sciences (China); H. Chen, Institute of Optics and Electronics (China); T. Tang, Institute of Optics and Electronics (China) and Graduate School of the Chinese Academy of Sciences (China)

$67221 \mathrm{~L} \quad$ Novel hole blocking material for organic light-emitting devices [6722-56]

J. YU, S. Lou, Y. Jiang, L. Li, Q. Li, Univ. of Electronic Science and Technology of China (China); X. Zhan, Institute of Chemistry (China)

$67221 \mathrm{M} \quad$ Research on special prism processing craft [6722-57]

C. Xue, F. Huo, Changchun Univ. of Science and Technology (China); H. Lv, Mcoptics Co., Ltd. (China)

$67221 \mathrm{~N} \quad$ Viewing angle analysis of integral imaging [6722-58]

H.-X. Wang, C.-H. WU, Y. Yang, L. Zhang, Univ. of Science and Technology Beijing (China)

672210 Organic light-emitting devices based on different hole transport materials [6722-59]

S. Lou, J. Yu, H. Lin, J. Wang, Y. Jiang, Univ. of Electronic Science and Technology of China (China)

$67221 \mathrm{P}$ Study on optical polishing of optical glass by means of ultrasonic-magnetorheological compound finishing [6722-60]

H. Wang, F. Zhang, H. Zhao, D. Luan, Y. Chen, Harbin Institute of Technology (China)

$67221 Q \quad$ Comparison of ion post treatment and laser conditioning of thin films [6722-61]

D. Zhang, P. Fan, X.-M. Cai, Shenzhen Univ. (China); J. Shao, Z. Fan, Shanghai Institute of Optics and Fine Mechanics (China)

$67221 \mathrm{R} \quad$ Analyzing the extrusion mould for aluminum profile [6722-62] W. Yun, Z. Xu, Y. Dai, P. Dong, G. Yuan, C. Lan, Jiangsu Univ. (China)

6722 is Inclusion initiated damage studies at repetition rate pulse laser [6722-63] F. Dai, Institute of Optics and Electronics (China) and Graduate School of the Chinese Academy of Sciences (China); S. Xiong, Y. Zhang, Institute of Optics and Electronics (China) 
6722 1T Characterization of novel nonlinear optical polymeric film fabricated from dye doped PMMA [6722-64]

L. Han, Y. Jiang, J.-S. YU, W. Li, P. Hao, C. Li, Univ. of Electronic Science and Technology of China (China)

$67221 \mathrm{U}$ Effect of technical parameter on optical constants of amorphous silicon thin film [6722-65] S.-B. Li, Z.-M. Wu, K.-P. Zhu, Y.-D. Jiang, W. Li, N.-M. Niao, Univ. of Electronic Science and Technology of China (China)

$67221 \mathrm{~V}$ Effect of annealing temperature on AIN thin films prepared by D.C. magnetism filter arc deposition [6722-66]

H. Liang, Y. Liu, C. Cai, Xi'an Univ. of Technology (China)

6722 IW Fabrication of ZnO thin film Schottky ultraviolet photodetector [6722-67]

B. Huang, G. He, Y. WU, L. Zhang, J. Li, D. Guo, S. Wu, Xiamen Univ. (China)

$67221 \mathrm{X}$ Laser shock wave and its applications [6722-68]

C. Yang, Y. Zhang, J. Zhou, Jiangsu Univ. (China); F. Zhang, Shazhou Vocational Institute of Technology (China); A. Feng, Jiangsu Univ. (China)

$67221 Y \quad$ Optimization of removal function for magnetorheological jet polishing [6722-69]

X. Zhang, Y. Dai, S. Li, X. Peng, National Univ. of Defense Technology (China)

$672212 \quad$ Study of optical properties of metallic photonic crystal [6722-70]

A. H. Aly, Chonnam National Univ. (South Korea) and Beni-Suef Univ. (Egypt); S.-W. Ryu, Chonnam National Univ. (South Korea)

672220 Design and fabrication of an infrared dichroic filter used for multi-channel image-forming system [6722-71]

W. Duan, D. Liu, F. Zhang, Shanghai Institute of Technical Physics (China)

672221 Theoretical analysis and experimental investigation on V-shape deformation by laser peening [6722-72]

$X$. Zhang, Anhui Univ. of Technology (China) and Jiangsu Univ. (China); Y. Zhang, J. Zhou,

Y. Gu, J. Cheng, Jiangsu Univ. (China)

672222 Fast speed MWIR imager for uncooled focal plane array [6722-73]

L. Lin, Soochow Univ. (China)

672223 Study on CCOS fabrication technology for super-smooth parabolic surface of light-weight SiC mirror [6722-74]

Q. XU, F. Wu, Y. Wan, L. Luo, P. Gao, Institute of Optics and Electronics (China)

672224 Indirect optical thickness monitoring with stationary test-slides for precision optical coatings [6722-75]

X. Yao, C. Xiong, C. Yang, N. Tong, Huazhong Institute of Electro and Optics (China)

672225 Method for characterization and simulation of non-axisymmetric aspheric rough surface [6722-76]

Y. F. Peng, Y. B. Guo, Xiamen Univ. (China) 
672226 Study on the attitude of dynamic missile based on vertical optical axes binocular vision system [6722-77]

X. Zhang, B. Zhang, Tianjin Univ. of Technology (China); Y. Lin, Tianjin Univ. (China); X. Li, Tianjin Univ. of Technology (China)

672227 Effects on residual stresses of Ti6Al4V alloy EBW by laser quenching [6722-78]

J. Lu, Jiangsu Univ. (China); Y. Zhang, Jiangsu Univ. (China) and East China Univ. Of Science and Technology (China)

672228 Design of broadband dielectric coatings for near-infrared Fabry-Perot interferometer [6722-79]

J. Wang, National Astronomical Observations/Nanjing Institute of Astronomical Optics and Technology (China) and Graduate School of Chinese Academy of Sciences (China); W. Mao, X. Cui, National Astronomical Observations/Nanjing Institute of Astronomical Optics and Technology (China)

672229 Influence of various doping ratio on optical and electronic performance of blue organic light-emitting diodes [6722-80]

J. Zhong, J. YU, L. Zhang, Y. Jiang, H. Wang, H. Lin, Univ. Of Electronic Science and Technology of China (China)

6722 2A Distributed optically integrated manufacture system based on CORBA [6722-81] M. Cen, Chongqing Univ. of Posts and Telecommunications (China); J. Jiang, Chongaing Univ. of Posts and Telecommunications (China) and Chongqing Univ. (China); X. Liu, Institute of Optics and Electronics (China); R. Hu, Sichuan Univ. (China)

6722 2B New design of optical focusing system from an axicon combination for laser microprocessing machine [6722-82]

H. Yao, Y. Zhang, X. Ye, J. LU, Jiangsu Univ. (China)

6722 2C Designing the actuator distribution of DM based on SPGD optimization [6722-83] $\mathrm{H}$. Yang, Institute of Optics and Electronics (China) and National Univ. of Defense Technology (China); C. Rao, Y. Zhang, W. Jiang, H. Yang, Institute of Optics and Electronics (China)

\section{Part Two}

6722 2D Novel automatic angular tracking method for fiber-optic alignment in butterfly laser module packaging [6722-84]

H. Shen, X. Wang, Harbin Institute of Technology, Shenzhen Graduate School (China)

6722 2E Micro-feed mechanism with high-resolution and large-stroke based on friction drive [6722-85]

H. Liu, Z. Lu, Harbin Institute of Technology (China)

$67222 \mathrm{~F} \quad$ Rotating sensing based on slow light coupled resonator structure with EIT-like property [6722-86]

C. Peng, Z. Li, A. Xu, Peking Univ. (China) 
$67222 G$ Design and fabrication of a non-polarizing broadband dichroic filter [6722-87]

X. Ma, D. Liu, Z. Zhu, D. Li, G. Chen, F. Zhang, Shanghai Institute of Technical Physics (China)

$6722 \mathrm{2H}$ Influence of laser beam on transport dynamics of Si nanoparticles by laser ablation [6722-88]

Y. Wang, W. Xu, Y. Zhou, L. Chu, Y. Hou, G. Fu, Hebei Univ. (China)

672221 Optimization of deposition uniformity in a planet rotation system with precise mask design [6722-89]

J. Luo, S. Chen, P. Ma, Chengdu Fine Optical Engineering Research Ctr. (China)

6722 2J Automatic alignment between two optical fiber collimators [6722-90]

J. XU, X. Wang, H. Shen, Harbin Institute of Technology, Shenzhen Graduate School (China)

$67222 \mathrm{~K}$ Effects of substrate temperature and annealing in air on optical properties of $\mathbf{A g}$ films prepared by thermal evaporation [6722-91]

J. Lv, F. Lai, Z. Huang, Y. Qu, R. Gai, Fujian Normal Univ. (China)

$6722 \mathrm{2L}$ Effects of substrate temperature and annealing on the structure and optical properties of ZnS film [6722-92]

X. Wu, F. Lai, Y. Lin, Z. Huang, R. Chen, Fujian Normal Univ. (China)

6722 2M Analysis of ring resonator of integrated optical waveguide gyroscope [6722-93]

X. Zhang, C. Ji, T. Zhang, Y. Cui, Southeast Univ. (China)

$67222 \mathrm{~N}$ Machining mode and error analysis in non-axisymmetric aspheric surface grinding [6722-94]

Z. Wang, Y. Guo, H. Huang, J. Gou, Xiamen Univ. (China)

672220 Long wavelength infrared dual field-of-view optical system [6722-95]

T. Xiong, C. Yang, Huazhong Institute of Electro-Optics (China)

6722 2P Research on locus planning in large scale non-axisymmetric aspheric surface machining [6722-96]

H. Huang, Y. Guo, Xiamen Univ. (China)

$67222 \mathrm{Q}$ Study on ITO/Ag/ITO multilayer film as the electrode of organic light-emitting diodes [6722-97]

L. Zhang, J. Yu, J. Zhong, H. Wang, Y. Jiang, J. Deng, Univ. of Electronic Science and Technology of China (China)

6722 2R Application of media with a negative refractive index in IR and visible frequencies [6722-98]

B. Liang, L. Feng, X. Zhang, Z. Li, J. Chen, S. Zhuang, Univ. of Shanghai for Science and Technology (China)

672225 Analysis of laser-induced damage threshold in dielectric optical film [6722-99] $X$. Shang, Sichuan Univ. (China) and Chengdu Fine Optical Engineering Research Ctr. (China); P. Ma, J. Hu, Chengdu Fine Optical Engineering Research Ctr. (China); R. Zhang, Sichuan Univ. (China) 
6722 2T Numerical and experimental study on SU-8 UV photolithography [6722-100]

L. Du, S. Zhu, J. Qin, C. Liu, Dalian Univ. of Technology (China)

$6722 \mathrm{2U}$ Calculation and structural analysis for the rigidity of air spindle in the single point diamond turning lathe [6722-101]

C. An, Harbin Institute of Technology (China) and Chengdu Fine Optical Engineering Research Ctr. (China); Q. XU, Chengdu Fine Optical Engineering Research Ctr. (China);

F. Zhang, Harbin Institute of Technology (China); J. Zhang, Chengdu Fine Optical

Engineering Research Ctr. (China)

6722 2V Matching the residual stress between Hafnia and silica for high reflective mirrors [6722-102] J. Hu, S. Cheng, P. Ma, J. Luo, Z. Wang, Chengdu Fine Optical Engineering Research Ctr. (China)

6722 2W Layer-by-layer assembled highly reflective optical coatings [6722-103]

L. Zhou, X. Li, H. YU, W. Li, Wuhan Univ. of Technology (China)

6722 2X Characterization of hydrogenated amorphous silicon thin films prepared by PECVD [6722-104]

Z.-M. Wu, S.-B. Li, W. Li, N.-M. Niao, Y.-D. Jiang, K.-P. Zhu, Univ. of Electronic Science and Technology of China (China)

$67222 \mathrm{Y}$ Temperature distribution and thermal stress in glass irradiated by dual $\mathrm{CO}_{2}$ lasers [6722-105] H. Lu, J. Junke, X. Wang, Huazhong Univ. of Science and Technology (China)

$67222 Z \quad$ Negative refraction phenomenon dependent on wave guide width [6722-106]

L. Feng, B. Liang, Z. Li, J. Chen, S. Zhuang, Univ. of Shanghai for Science and Technology (China)

672230 Research on rheological property of magnetorheological fluid [6722-107]

H. Wang, A. Tian, Q. Tang, Z. Chen, B. Liu, Xi'an Technological Univ. (China)

672231 Crucial fabrication with rounded diamond cutting tools [6722-108]

T. Sun, Z. Q. Li, W. J. Zong, S. Dong, K. Cheng, Harbin Institute of Technology (China);

Z. Z. Zhao, Liaoning Univ. of Technology (China)

672232 Morphology of femtosecond laser-induced structural changes in $\mathrm{MgAl}_{2} \mathrm{O}_{4}$ crystal [6722-109]

B.-H. YU, Xinyang Normal Univ. (China) and Huazhong Univ. of Science and Technology

(China); N.-L. Dai, Y.-H. Li, Q.-G. Zheng, P.-X. Lu, Xinyang Normal Univ. (China)

672233 Study on laser anti-damage film of 532nm and 1064nm Nd:YAG laser [6722-110]

J. Tang, G. Liu, X. Fu, Y. Zhao, Changchun Univ. of Science and Technology (China);

J. Wang, Northeast Normal Univ. (China)

672234 Study on electroluminescent characteristics of two novel fluorene/carbazole copolymers [6722-111]

F. Suo, J. YU, J. Deng, Y. Jiang, Univ. of Electronic Science and Technology of China

(China); R. Wang, T. Liu, Fudan Univ. (China) 
672235 Design and manufacture of broadband high-reflective film [6722-112]

J. Zhang, X. Fu, Changchun Univ. of Science and Technology (China)

672236 High speed lapping hyperboloid by means of a lapping tool bending method [6722-113]

J. Yang, Changchun Univ. of Science and Technology (China) and Jilin Province

Economics and Management Cadres College (China); C. Tian, H. Yang, Z. Hao,

Changchun Univ. of Science and Technology (China)

672237 Influence of ambient gas on the microstructural properties of Er-doped nanocrystalline Si film fabricated by pulsed laser ablation [6722-114]

Y. Zhou, L. Chu, P. Duan, W. Xu, Y. Wang, G. F, Hebei Univ. (China)

672238 Optimization and test of two-dimensional birefringent low-pass filter [6722-115]

X. Qi, Zhejiang Univ. (China) and Anhui Normal Univ. (China); B. Lin, X. Cao, Zhejiang Univ. (China)

672239 Design of F-Theta lens used in laser marking machine [6722-116]

Y. Ji, W. Shen, Soochow Univ. (China)

6722 3A Research on polishing technology based on surface contact MRF [6722-117]

Z. Chen, Z. Guo, W. Liu, L. Hang, W. Wang, Xi'an Technological Univ. (China)

6722 3B Electronic trap effect of spectral sensitizing dye adsorbed on the surface of the film of silver chloride microcrystals [6722-118]

X.-W. Li, J.-X. Zhang, R.-X. Zhang, W.-D. Lai, L. Li, X.-H. Dai, G. Fu, Hebei Univ. (China)

6722 3C Novel method of designing deformable polishing lap [6722-119]

Z. Hu, Institute of Optics and Electronics (China), Graduate School of the Chinese

Academy of Sciences (China), and Yantai Univ. (China); N. Ling, Institute of Optics and

Electronics (China)

6722 3D Micro topography of different material surface by solid abrasive lapped at high speed

[6722-120]

C. Tian, J. Yang, J. Fan, H. Zhou, Changchun Univ. of Science and Technology (China)

$67223 \mathrm{E} \quad 1.06 \mu \mathrm{M} / \mathrm{LWIR}$ dual band antireflection coatings for optical windows [6722-121]

C. Xiong, L. Yang, Q. Li, Huazhong Institute of Electro-Optics (China)

$67223 \mathrm{~F}$ Crystallization of amorphous Si thin films by means of laser and thermal annealing from the viewpoint of energy [6722-122]

G. Fu, Z. Deng, Y. Wang, K. Zhang, Hebei Univ. (China)

6722 3G Photoelectron decay kinetics of cubic silver chloride microcrystal film adsorbing plentiful dye excited by laser [6722-123]

R. Zhang, J. Zhang, W. Lai, Y. Hu, X. Dai, L. Han, X. Li, Hebei Univ. (China)

$67223 \mathrm{H}$ Dynamics analysis of photoelectron decay in cubic AgCl microcrystals by sulfur sensitization [6722-124]

X. Li, Y. Hu, R. Zhang, J. Zhang, G. Dong, S. Yang, G. Fu, Hebei Univ. (China) 
672231 STABCC: a new 3D surface topography algorithm based on contourlet transform and correlation theory [6722-125]

J. Wang, Huazhong Univ. of Science and Technology (China) and China Jiliang Univ. (China); Y. Kang, House Mapping and Conveying Institute of Zhe Jiang (China); L. Xu, Huazhong Univ. of Science and Technology (China)

6722 3J Rock fracture image acquisition and analysis [6722-126]

W. Wang, J. Zongpu, Henan Polytechnic Univ. (China); L. Chen, Chongqing Three Gorges Univ. (China)

6722 3K Comparison of global thresholding algorithms on rock joint images [6722-127]

L. Chen, Chongqing Three Gorges Univ. (China); W. Wang, Henan Polytechnic Univ.

(China); H. Liao, Chongaing Three Gorges Univ. (China)

6722 3L Study on chemical mechanical polishing process of lithium niobate [6722-128] S. Wang, Y. Liu, Z. Li, Hebei Univ. of Technology (China)

$67223 \mathrm{M} \quad$ Embedded design on optical coherence tomography control system [6722-129] Z. Wang, X. Wang, G. Zhong, Zhejiang Univ. (China)

$67223 \mathrm{~N} \quad$ Study of holographic grating in porous silicon optical waveguides [6722-130] Z. Jia, X. Lü, C. Tu, Xinjiang Univ. (China)

672230 Study on anti-laser high-reflection coating [6722-131] H. Wang, BaiCheng Teacher College (China); X. Fu, Chang Chun Univ. of Science and Technology (China); X. Chen, China Trade Association For Anti-Counterfeiting (China)

6722 3P Study on the performance of organic light-emitting diode with N,N'-bis(3-methylphenyl)$\mathbf{N}, \mathbf{N}^{\prime}$-diphenylbenzidine doped in polystyrene as hole transporting layer [6722-132] J. Deng, G. Xie, J. Yu, F. Suo, W. Li, Y. Jiang, Univ. of Electronic Science and Technology of China (China)

$67223 Q \quad$ Deposition and applications of high performance $\mathrm{YF}_{3}$ thin films [6722-133] L. Yang, C. Xiong, M. Zhu, Huazhong Institute of Electro-Optics (China)

$67223 R$ Design and fabrication of soft $X$-ray transmission phase gratings [6722-134] K. Qiu, X. Xu, Y. Liu, Y. Hong, S. Fu, Univ. of Science and Technology of China (China)

672235 Design of erbium-doped fiber laser based on linear multi-cavity [6722-135] H. Pang, H. Cui, H. Lian, R. Zhao, B. Hu, Y. Wang, Hebei Univ. of Science and Technology (China)

672231 DLC/BP ultra durable LWIR protective coatings for ZnS windows [6722-136] Q. Li, S. Liu, C. Xiong, Huazhong Institute of Electro-Optics (China)

$67223 U$ Design of dual-FOV refractive/diffractive LWIR optical system [6722-137]

J. Zhang, L. Wang, Changchun Institute of Optics, Fine Mechanics and Physics (China) and Graduate School of Chinese Academy of Sciences (China); X. Zhang, Changchun Institute of Optics, Fine Mechanics and Physics (China) 
$67223 \mathrm{~V}$ Effects on residual stresses of aluminum alloy LC4 by laser shock processing [6722-138] Y. Zhang, Jiangsu Univ. (China) and East China Univ. of Science and Technology (China); J. Lu, D. Kong, H. Yao, C. Yang, Jiangsu Univ. (China)

6722 3W Fabrication of supersmooth surfaces with low subsurface damage [6722-139] Z. Shen, B. Ma, Z. Wang, Tongji Univ. (China); Y. Ji, T. Liu, H. Liu, Tianjin Jinhang Institute of Technology Physics (China)

$67223 \mathrm{X}$ High quality $\mathrm{HfO}_{2}$ thin films prepared by reactive ion beam assisted deposition [6722-140] C. Wang, Y. Jin, J. Shao, Z. Fan, Shanghai Institute of Optics and Fine Mechanics (China)

$67223 Y$ Research on ITO transparent electromagnetic shielding coatings for E-O system [6722-141] M. Zhu, Huazhong Institute of Electro-Optics (China) and Huazhong Univ. of Science and Technology (China); C. Xiong, Q. Lee, Huazhong Institute of Electro-Optics (China)

672237 Low doping white phosphorescent organic light-emitting diodes [6722-142]

Y. Jiang, J. Wang, S. Lou, H. Lin, J. Yu, Univ. of Electronic Science and Technology of China (China)

$672240 \quad$ Laser cutting for slotted oil pipes [6722-143]

C. He, Huazhong Univ. of Science and Technology (China)

$672241 \quad$ Light extraction from organic light emitting diode [6722-144]

W. Chen, G. Li, F. Wu, Univ. of Electronic Science and Technology of China (China)

672242 Bright-yellow molecular organic light-emitting diodes based on two novel silole derivatives [6722-145]

L. Li, W. Li, J. Yu, Q. Li, S. Lou, Y. Jiang, Univ. of Electronic Science and Technology of China (China); X. Zhan, Institute of Chemistry (China)

672243 Properties of DC magnetron sputtered indium-tin oxide films with the assistance of tiny $\mathrm{H}_{2} \mathrm{O}$ vapor at low temperature [6722-146]

H. Lin, J. Yu, S. Lou, J. Wang, Y. Jiang, Univ. of Electronic Science and Technology of China (China);

$672244 \quad$ High bright blue organic light-emitting diodes based on a novel silole derivative [6722-147] Q. Li, J. YU, L. Li, Y. Jiang, S. Lou, Univ. of Electronic Science and Technology of China (China); X. Zhan, Institute of Chemistry (China)

672245 Methods to determine best-fit sphere for off-axis aspheric surface [6722-148]

L. Zheng, National Astronomical Observatories/Nanjing Institute of Astronomical Optics and Technology (China) and Graduate School of Chinese Academy of Sciences (China);

Z. Zhu, Nanjing Institute of Astronomical Optics and Technology (China)

672246 Colony image acquisition and segmentation [6722-149]

W. X. Wang, Chongqing Univ. of Posts and Telecommunications (China) and Henan Polytechnic Univ. (China)

672247 Design and implementation of lens for fast biochip detection system [6722-150]

Q. Ye, Y. Liu, W. Zhou, J. Tian, Nankai Univ. (China) 
672248 Grating vibration sensor with digital direction identification [6722-151]

J. Zhuge, Tianjin Univ. (China) and Tianjin Univ. of Science and Technology (China); Z. Zeng, Tianjin Univ. (China); S. Li, Tianjin Univ. of Science and Technology (China); Y. Zhang,

X. Zhan, Tianjin Univ. (China)

672249 All-fiber acousto-optic intensity modulator using surface acoustic wave [6722-152] K. Yu, W. An, T. Liu, S. Li, S. He, S. Hu, Beijing Univ. of Technology (China)

6722 4A lon beam figuring system in NUDT [6722-153]

L. Zhou, X. Xie, Y. Dai, C. Jiao, S. Li, National Univ. of Defense Technology (China)

6722 4B ZnO nanocrystalline thin films prepared by ion beam enhanced deposition method [6722-154]

N. Y. Yuan, J. H. Li, Z. J. He, G. Li, X. Q. Wang, Jiangsu Polytechnic Univ. (China)

6722 4C Hardness of CNx films deposited by MCECR plasma sputtering [6722-155]

C. Cai, J. Li, Q. Mi, W. Ma, Y. Yan, H. Liang, Xi'an Technological Univ. (China)

6722 4D Hardness of DLC deposited by pulsed arc [6722-156]

C. Cai, Q. Mi, W. Ma, Y. Yan, H. Liang, Xi'an Technological Univ. (China)

6722 4E Optical passive athermalization for infrared zoom system [6722-157]

S. Li, C. Yang, J. Zheng, N. Lan, T. Xiong, Y. Li, Huazhong Institute of Electro-Optics (China)

6722 4F Design of Cassegrain-Schmidt optical system [6722-158]

P. Hao, K. Li, Z. Wang, Tongji Univ. (China)

6722 4G Design and application of non-spherical focus mirror based on analytical function theory [6722-159]

R. Zhong, X. Tang, Huazhong Univ. of Science and Technology (China); Q. Wang,

Huazhong Normal Univ. (China); C. Wang, Z. Li, Huazhong Univ. of Science and Technology (China)

$67224 \mathrm{H} \quad 1.8$-in. 128×160 full color passive matrix OLED [6722-160]

G. Yang, Q. Jiang, J. Cheng, J. Zhong, W. Chen, X. Q. Wei, J. Wang, H. Lin, M. Xie, Univ. of Electronic Science and Technology of China (China); S. Chen, Zhejiang Yankon Group Corp., Ltd. (China)

$672241 \quad$ Cleaning of ITO glass with carbon dioxide snow jet spray [6722-161]

J. Li, T. Qi, S. Li, G. Zhao, Univ. of Electronic Science and Technology of China (China)

$67224 \mathrm{~J}$ Study on the spectral properties of Yb:KGW crystal [6722-162]

W. Yang, J. WU, L. Guo, S. Lv, S. Feng, Y. Chen, J. Yang, Fujian Normal Univ. (China)

6722 4K Optical system design of multi-spectral and large format color CCD aerial photogrammetric camera [6722-163]

Y. Qian, T. Sun, Institute of Optics and Electronics (China) and Graduate School of the Chinese Academy of Sciences (China); X. Gao, W. Liang, Institute of Optics and Electronics (China) 
$67224 \mathrm{~L}$ Scaling and analyzing the influence of fluid surface of fluid with nano-granular through speckle pattern experiment [6722-164]

$X$. Wang, Changchun Institute of Optics, Fine Mechanics and Physics (China); Y. Wang, $X$. Li, Changchun Institute of Optics, Fine Mechanics and Physics (China) and Graduate School of the Chinese Academy of Sciences (China); J. W. Seo, Hongik Univ. (South Korea)

$67224 \mathrm{M}$ Optical and electrochemical properties of $\mathrm{Ni}$ doped $\mathrm{WO}_{3}-\mathrm{MoO}_{3}$ films prepared by sol-gel process [6722-165]

Z. Li, M. Zhang, Y. Zhang, Naval Univ. of Engineering (China)

$67224 \mathrm{~N} \quad$ Narcissus analysis for cooled staring IR system [6722-166]

F.-Y. He, Changchun Institute of Optics, Fine Mechanics and Physics (China) and Graduate School of the Chinese Academy of Sciences (China); J.-C. Cui, S.-L. Feng, X. Zhang,

Changchun Institute of Optics, Fine Mechanics and Physics (China)

672240 Study on computer controlled polishing machine with small air bag tool [6722-167]

Y. Wang, Y. Ni, J. YU, Soochow Univ. (China)

$67224 \mathrm{P} \quad$ Fabrication of aspherical liquid lens controlled by electrostatic force [6722-168]

Z. Zhan, K. Wang, Univ. of Science and Technology of China (China)

Author Index 
Downloaded From: https://www.spiedigitallibrary.org/conference-proceedings-of-spie on 26 Apr 2023

Terms of Use: https://www.spiedigitallibrary.org/terms-of-use 


\title{
Conference Committee
}

\author{
Conference Chairs
}

Li Yang, Committee of Optical Manufacturing Technology, COS (China)

Yaolong Chen, Berliner Glas KgaA (Germany)

Ernst-Bernhard Kley, Friedrich-Schiller-Universität Jena (Germany)

Rongbin Li, Hong Kong Polytechnic University (Hong Kong China)

Program Committee

Paul Kloceck, ELCAN Optical Technologies (USA)

Qiming Xu, Beijing Institute of Technology (China)

Jingchi Yu, Suzhou University (China)

Hans Lauth, Jenoptik Laser, Optik System, GmbH (Germany)

Changshun Hui, Tianjin Jinhang Institute of Technology Physics (China)

Jinliang Zhang, Xi'an Institute of Applied Optics (China)

Matthias Pfaff, OptoTech Optikmaschinen GmbH (Germany)

Wei Li, Chengdu Fine Precision Optical Engineering Research Center (China)

\section{Session Chairs}

2-1 Shengyi Li, National University of Defense Technology (China)

2-2 Shangming Wen, Institute of Optics and Electronics, CAS (China)

2-3 Qiming Xin, Beijing Institute of Technology (China)

2-4 Haiying Wang, Institute of Optics and Electronics, CAS (China)

2-5 Xuejun Zhang, Changchun Institute of Optics, Fine Mechanics and Physics (China)

\section{2-6 Bo Wang (China)}


Downloaded From: https://www.spiedigitallibrary.org/conference-proceedings-of-spie on 26 Apr 2023

Terms of Use: https://www.spiedigitallibrary.org/terms-of-use 


\section{Symposium Committees}

Honorary Chair

Daheng Wang, Chinese Academy of Sciences (China) and Chinese Academy of Engineering (China)

Symposium General Chair

Bingkun Zhou, Chinese Optical Society (China) and Chinese Academy of Sciences (China)

Symposium General Cochairs

Paul McManamon, Air Force Research Laboratory (USA)

Jianlin Cao, Ministry of Science and Technology (China)

Yudong Zhang, Institute of Optics and Electronics, CAS (China)

James C. Wyant, Optical Sciences Center, University of Arizona (USA)

Advisory Committee

Wenhan Jiang, Chinese Academy of Engineering (China)

Robert R. Shannon, Optical Sciences Center, University of Arizona (USA)

Junhua Pan, Chinese Academy of Engineering (China)

Xun Hou, Chinese Academy of Sciences (China)

Organizing Committee

Yudong Zhang, Chair, Institute of Optics and Electronics, CAS (China)

Guoqiang Ni, Cochair, Chinese Optical Society (China)

Li Yang, Committee of Optical Manufacturing Technology, COS (China)

Jinxue Wang, SPIE Technical Advisor (USA) and Raytheon Santa Barbara Remote Sensing (USA)

Walter C. Czajkowsly, Eastman Kodak Company, APOMA (USA)

Zheng Cui, Rutherford Appleton Laboratory (United Kingdom)

Hans Lauth, Jenoptik Laser, Optik Systeme, GmbH (Germany)

Rongbin Li, Hong Kong Polytechnic University (Hong Kong China)

Roland Geyl, REOSC Optics, SAGEM (France) 
Richard Freeman, Zeeco Company Ltd. (United Kingdom)

Yaolong Chen (Germany)

Jianlin Zhao, Northwestern Polytechnic University (China)

Ernst-Bernhard Kley, Friedrich-Schiller-Universität Jena (Germany)

Hexin Wang, Carl Zeiss AG (Germany)

Kathleen A. Richardson, CREOL, University of Central Florida (USA)

Mary G. Turner, InfoTek Information Systems (USA)

Matthias Pfaff, OptoTech Optikmaschinen GmbH (Germany)

Michael Sander, Satisloh GmbH (Germany)

Mike Conroy, Taylor Hobson Ltd. (United Kingdom)

Program Committee

Hu Yang, Chair, Institute of Optics and Electronics, CAS (China)

Wei Zhao, Xi' an Institute of Optics and Fine Mechanics, CAS (China)

Yuwen Qin, Natural Science Foundation of China (China)

Huilin Jiang, Changchun University of Science and Technology

(China)

Jingchi Yu, Suzhou University (China)

Xiangqun Cui, Nanjing Institute of Astronomical Optics and Technology (China)

David D. Walker, University College London (United Kingdom)

Qiming Xin, Beijing Institute of Technology (China)

Yuri Storyalove, State Optics Institute (Russia)

Hans J. Kaercher, MANTechnologies AG (Germany)

Fan Wu, Institute of Optics and Electronics, CAS (China)

Mike DeMarco, QED Technologies (USA)

Wei Li, Chengdu Fine Precision Optical Engineering Research Center (China)

Xuejun Zhang, Changchun Institute of Fine Mechanics and Physics, CAS (China)

Masakazu Miyashita, Ashikaga Institute of Technology (Japan)

Changyuan Han, Optical Testing Technology Committee, COS

(China)

Paul Kloceck, ELCAN Optical Technologies (USA)

Secretary General of the Symposium

Li Yang, Committee of Optical Manufacturing Technology, COS (China) 


\section{Introduction}

Optical manufacturing technology has seen tremendous progress especially during the last 10 years both in China and abroad. It plays remarkable supporting and enabling roles in many industries and contributes to technology and society development. Optical manufacturing technology has become a very important interdisciplinary field of manufacturing science and optical science. It is closely associated with developments in information technologies, bioscience, materials, nanotechnologies, etc. At the same time, optical manufacturing has developed into a new global business involving optics, optoelectronics, and photonics in the world economy system. Today, as China becomes an integral part of the global economy, it is hard to find an area of optical manufacturing or optical market that doesn't involve the close cooperation between China and the rest of the world.

To satisfy the needs for timely exchanges of optical manufacturing technologies and market information, the first international symposium on Advanced Optical Manufacturing and Testing Technology (AOMATT) was sponsored and organized by the Chinese Optics Society (COS), The Institute of Optics and Electronics (IOE) of Chinese Academy of Science (CAS), and SPIE in 2000. Prof. WANG Daheng, a leading authority of Chinese optics and optical engineering and an academician of both the Chinese Academy of Science and Chinese Academy of Engineering, chaired the first successful AOMATT symposium in Chengdu, China. The first AOMATT in 2000 resulted in 106 papers published in the Proceedings of SPIE, Vol. 4231. A much larger second AOMATT meeting was held in Xian, China, in 2005. It resulted in 359 papers published in the Proceedings of SPIE, Vols. 6148-6150. The third AOMATT symposium came back to Chengdu, China, in July 2007. By all accounts, it was even a bigger success. More than 700 delegates from all over the world attended the opening ceremony and plenary session on the first day of the symposium. A total of 483 oral and poster papers were presented at the symposium. They are published in the Proceedings of SPIE, vols. 6721-6724.

Professor ZHOU Bingkun, AOMATT 2007 Symposium General Chair, President of the Chinese Optical Society, and Academician of Chinese Academy of Science, chaired the opening ceremony and the plenary presentation, and gave its congratulations to the symposium in his opening speech. Professor CAO Jinghua, Vice Director of the Bureau of International Co-operation of Chinese Academy of Science, attended the opening ceremony and gave a warm opening speech. Dr. Philip Stahl from NASA Marshall Space Flight Center, a member of SPIE's Board of Directors and Vice President of ICO, represented SPIE at the symposium and delivered the first symposium plenary presentation entitled "James Webb Space Telescope: The First Light Machine." It was warmly received by the symposium delegates. Other symposium plenary speakers include Dr. Bernard Delabre from 
ESO of Germany, Dr. Eric Ruch from REOSC of France, Dr. Jim Burge from the University of Arizona of USA, Dr. David Walker from Univ. College London of UK, Dr. Yoshiharu Namba from Chubu University of Japan, Dr. Tadashi Hatano from Tohoku University of Japan, Dr. Masaomi Kameyama from Nikon Corporation of Japan, Dr. Xiangang Luo from IOE of China, and Dr. Sen Han from Veeco Corporation, USA. The plenary presentations have given symposium delegates the opportunity to learn about the latest developments in large mirror and telescope technology, advanced optical manufacturing technology, optical testing, and nanotechnologies. The symposium has provided an excellent platform for all delegates to network with each other, review progresses in their fields, discuss future technology and market trends, explore collaboration and business opportunities, etc.

We are delighted that each new AOMATT symposium is more successful than the last. AOMATT has established itself as a must-attend leading optical design and manufacturing symposium in China. We are confident the meeting will get even better in the future and become a well-known international symposium. We would like to express our sincere appreciation to all organizations and individuals who have contributed to the success of AOMATT. We want to thank all authors and symposium delegates for attending the symposium and sharing their research and development with their colleagues around the world. The next AOMATT symposium will be held in China in 2009. We are looking forward to seeing you all at an even more successful AOMATT.

Li Yang

Secretary General, AOMATT 2000, 2005, 2007

Chairman of the Committee on Optical Manufacturing Technology of Chinese

Optical Society

Jinxue Wang

Deputy Secretary General, AOMATT 2007

Raytheon Santa Barbara Remote Sensing 


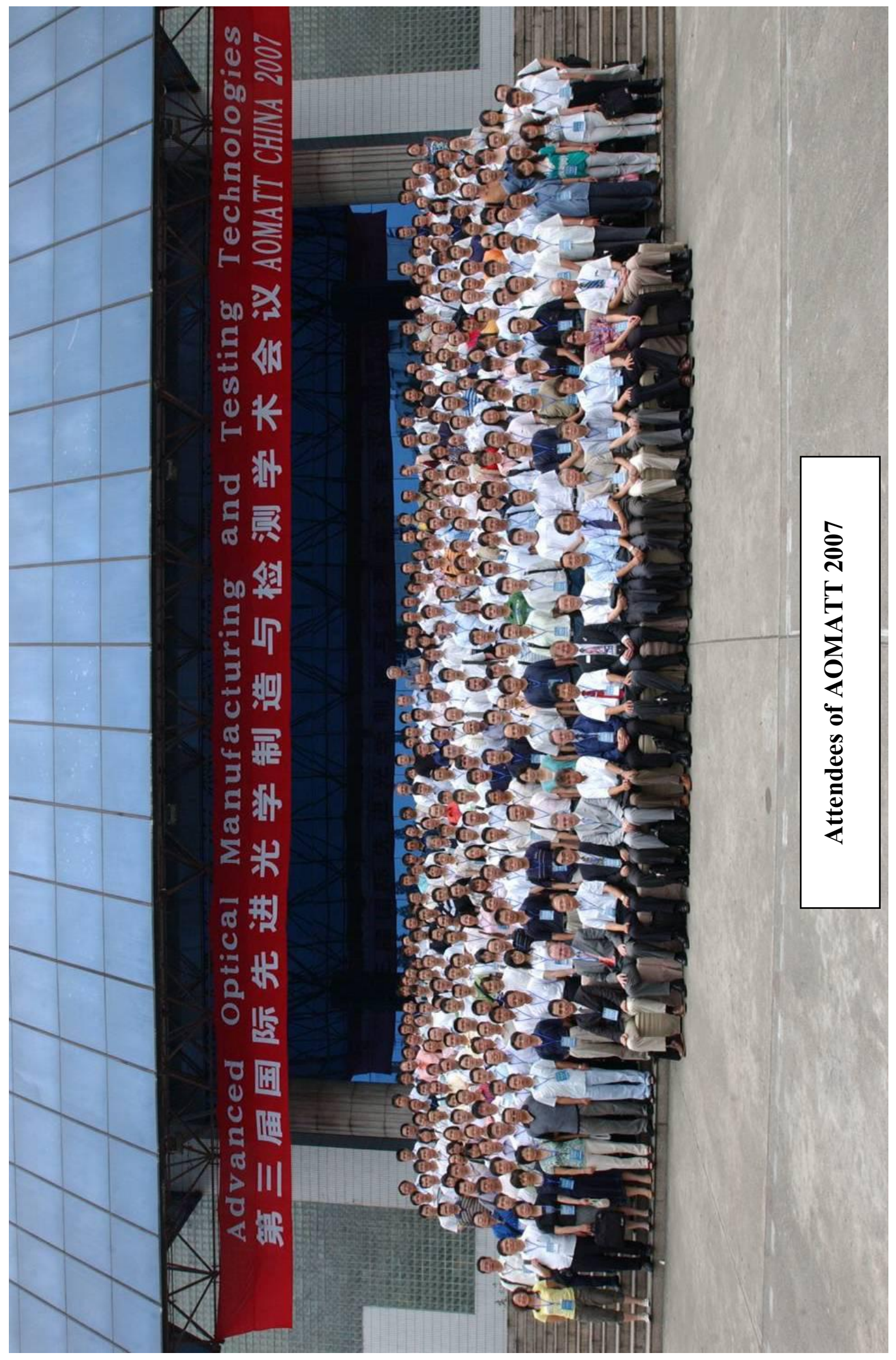


Downloaded From: https://www.spiedigitallibrary.org/conference-proceedings-of-spie on 26 Apr 2023

Terms of Use: https://www.spiedigitallibrary.org/terms-of-use 